\title{
The role of G196A polymorphism in the brain-derived neurotrophic factor gene in the cause of Parkinson's disease: a meta-analysis
}

Received: 7 June 2005/ Accepted: 3 August 2005/ Published online: 20 September 2005

(C) The Japan Society of Human Genetics and Springer-Verlag 2005

\begin{abstract}
The association between Parkinson's disease (PD) and the G196A polymorphism in the brain-derived neurotrophic factor (BDNF) gene has been investigated in several case-control studies, producing contradictory results: one study indicated that homozygocity of AA is associated with PD, another study produced the opposite result, whereas other studies found no association. To investigate these contradictory findings, a metaanalysis of all available association studies between the G196A polymorphism and the risk of developing PD was conducted. Four out of six identified studies included populations of East Asian descent, and two included populations of European descent (Whites). Overall, the meta-analysis of the allele contrast (A vs $G$ ) suggested large heterogeneity between studies $(P=0.07$, $I^{2}=51 \%$ ) and no association between G196A and the risk of developing $\mathrm{PD}$ : random effects odds ratio $(\mathrm{OR})=1.00[95 \% \mathrm{CI}(0.85,1.18)]$. The sensitivity analysis (exclusion of two studies: one East Asian and one White) with the controls not in Hardy-Weinberg equilibrium showed large heterogeneity $\left(P=0.10, I^{2}=52 \%\right)$ and no significant association: random effects $\mathrm{OR}=0.94$ $[95 \%$ CI $(0.77,1.15)]$. The subgroup analyses for East Asians and Whites produced no significant association. In addition, the contrast of homozygotes, and the dominant and recessive models for allele $\mathrm{A}$ did not support a major role for this polymorphism in the pathogenesis of PD. There were no sources of bias in the selected studies, and the differential magnitude of effect in large vs small studies was not significant. The metaanalysis results suggest that the involvement of the
\end{abstract}

E. Zintzaras $(\bowtie)$

Department of Biomathematics, University of Thessaly School of Medicine, Papakyriazi 22, 41222 Larissa, Greece

E-mail: zintza@med.uth.gr

Tel.: + 30-2410-565270

Fax: +30-2410-565270

G.M. Hadjigeorgiou

Neurogenetics Unit, Department of Neurology, University Hospital of Larissa, University of Thessaly School of Medicine, Papakyriazi 22, 41222 Larissa, Greece
BDNF gene in susceptibility to PD merits further exploration with larger and more rigorous population association studies.

Keywords Parkinson's disease - G196A ·

Polymorphism - Brain-derived neurotrophic factor .

BDNF $\cdot$ Meta-analysis

\section{Introduction}

Parkinson's disease (PD) is a common ( $1 \%$ at age 65 ; $4-5 \%$ at age 85 ), age-associated neurodegenerative disease, the clinical manifestations of which include bradykinesia, rest tremor, rigidity, gait abnormalities, and postural instability (Dawson and Dawson 2003). Recent studies implicate both genetic (Piccini et al. 1999; Sveinbjornsdottir et al. 2000) and environmental (Schapira 1997) factors in the pathogenesis of PD.

The brain-derived neurotrophic factor (BDNF) gene encodes a nerve growth factor, and is highly expressed in the nervous system (Holsinger et al. 2000; Murer et al. 2001). Since BDNF promotes the survival of dopaminergic neurons in the substantia nigra, and expression of BDNF is reduced in PD substantia nigra, it seems that a genetic variation in BDNF, e.g. the G196A (Val66Met) polymorphism, might affect the risk for PD (Hyman et al. 1991; Mogi et al. 1999). The G196A BDNF polymorphism plays a role in human memory and hippocampal function, and exerts these effects by impacting intracellular trafficking and activity-dependent secretion of BDNF (Egan et al. 2003).

Momose et al. (2002) reported that homozygocity (AA) for the G196A polymorphism of the BDNF gene is significantly more frequent in idiopathic PD patients than in normal controls, although there was no allele effect. Since then, a number of case-control studies investigating the association between the G196A polymorphism in the BDNF gene and PD have been conducted, but the results concerning the relationship 
between the risk of developing PD and the G196A mutation were inconclusive. One study (Masaki et al. 2003) clearly contradicted the results of Momose et al. (2002), while other studies reported no genetic association (Hakansson et al. 2003; Hong et al. 2003; Parsian et al. 2004; Nishimura et al. 2005). However, the significant associations described in single studies were rather marginal and are, therefore, subject to controversy (Masaki et al. 2003). In an attempt to resolve these contradictory results, a meta-analysis (Lau et al. 1997) of all available studies relating the G196A polymorphism of the BDNF gene to the risk of developing PD is presented here.

\section{Materials and methods}

Selection of studies

All studies that investigate the association of the G196A (Val66Met) polymorphism in the BDNF gene with the development of PD published before April 2005 were considered in the meta-analysis. The studies were identified by extended computer-based searches of the PubMed database. As a search criterion we used the following: (BDNF or "brain-derived neurotrophic factor" or V66M or Val66Met or G196A) and (PD or Parkinson's) and association.

The publications thus retrieved were read in their entirety in order to assess their appropriateness for inclusion in this meta-analysis. All references cited in the studies were also reviewed to identify additional published work not indexed by the PubMed database. Abstracts, case reports, editorials, and review articles were excluded. The search was restricted to articles in English. Case-control studies that determined the distribution of the G196A genotype in cases with non-familial PD and in controls free of PD were eligible for inclusion in the meta-analysis. The distribution of genotypes in the control group was tested for Hardy-Weinberg equilibrium (HWE) using an exact test (Weir 1996) implemented by GDA software (Lewis and Zaykin 2001). Studies based on pedigree data were excluded since they investigate linkage (Zintzaras and Ioannidis 2005) and not association.

\section{Data extraction}

From each study the following information was extracted: first author, journal, publication year, racial descent of study population, demographics, matching, validity of the genotyping method, and the number of cases and controls for each G196A genotype. The frequencies of the alleles were calculated, for the cases and the controls, from the corresponding genotype distributions. In addition, it was recorded whether the genotyping in each study was blinded to clinical status.
Meta-analysis

The meta-analysis examined the overall association of the A allele with the risk of PD relative to the G allele, and the contrast of homozygotes AA vs GG, the recessive model for the A allele: contrast $A A$ vs $(A G+G G)$, and the dominant model for the A allele: contrast $(\mathrm{AG}+\mathrm{AA})$ vs GG. All associations were indicated as odds ratios (ORs) with the corresponding 95\% confidence interval (CI). A pooled OR was then estimated based on individual ORs.

Heterogeneity between studies was tested using the $Q$ statistic (Cochran 1954). Heterogeneity was considered statistically significant if $P<0.10$. Heterogeneity was quantified with the $I^{2}$ metric, which is independent of the number of studies in the meta-analysis $\left(I^{2}<25 \%\right.$ : no heterogeneity; $I^{2}=25-50 \%$ : moderate heterogeneity; $I^{2}=50-75 \%$ : large heterogeneity; $I^{2}>75 \%$ : extreme heterogeneity; Higgins et al. 2003). The pooled OR was estimated using fixed effects (FE; Mantel-Haenszel) and random effects (RE; DerSimonian and Laird) models (Whitehead 2002). Random effects modelling assumes a genuine diversity in the results of the studies, and it incorporates the calculations of a between-study variability; it therefore tends to provide wider CIs. When there is heterogeneity between studies then the pooled OR is estimated using the RE model. Adjusted estimates of OR were considered whenever possible in a separate analysis. A cumulative meta-analysis (Lau et al. 1992; Whitehead 1997) and recursive meta-analysis were carried out in order to evaluate the trend of pooled OR for the allele contrast (A vs $G$ ) in time. The differential magnitude of effect in large vs small studies (or publication bias) (Ioannidis et al. 2003; Zintzaras et al. 2005), for the allele contrast, was tested using the Egger regression test for funnel plot asymmetry (Egger et al. 1997) and the Begg-Mazumdar test, which is based on Kendall's tau (Begg and Mazumdar 1994). Whether the OR in the first study vs the pooled OR of the subsequent studies were different beyond chance $(P<0.05)$ was assessed using the $z$-statistic (Ioannidis et al. 2003). The meta-analysis consisted of the main analysis, which includes all available data, the subgroup analysis of each racial descent (Zintzaras et al. 2005), and sensitivity analyses to examine the effect of excluding specific studies, such as studies with controls that are not in HWE.

Analyses were performed using Meta-Analyst (Joseph Lau, Boston, MA, 1998), SAS software, and CVF90 with IMLS library (Whitehead 2002; Zintzaras and Hadjigeorgiou 2004; Zintzaras and Stefanidis 2005; Zintzaras et al. 2005).

\section{Results}

\section{Eligible studies}

The literature review identified 47 titles in PubMed that met the search criteria. In one study, PD families were 
screened with three microsatellite markers located in the BDNF region, while another study reported analysis of three BDNF simple sequence length polymorphisms in PD patients (Wirdefeldt et al. 2003; Liu et al. 2005). Both these studies were excluded from meta-analysis because they provided no data for the G196A polymorphism. Seven studies investigating the association between the BDNF gene G196A polymorphism and PD met the inclusion criteria; however, one study (Toda et al. 2003) included cases and controls already reported by another study (Momose et al. 2002) and was therefore excluded (Table 1). The earliest study was published in 2002 (Momose et al. 2002) and the latest study in 2005 (Nishimura et al. 2005). In four studies (Momose et al. 2002; Hong et al. 2003; Masaki et al. 2003; Nishimura et al. 2005) the subjects were of East Asian descent, and in the remaining two studies (Hakansson et al. 2003; Parsian et al. 2004) the subjects were referred to as Whites (European descent).

The average age of PD patients ranged from 54.1 to 68.2 years. The distribution of gender was reported in three studies (Momose et al. 2002; Hong et al. 2003; Nishimura et al. 2005). One study did not provide any demographic details for the controls (Hakansson et al. 2003). In two studies, the controls were age-sex matched to the PD cases (Masaki et al. 2003; Parsian et al. 2004).

In one study (Nishimura et al. 2005) the diagnosis criteria for PD were not reported, in the remaining studies, the cases were well-defined, and followed similar inclusion criteria. In Momose et al. (2002) and Hakansson et al. (2003), 5\% and 3\% of cases, respectively, had a positive family history. In all studies, genotyping of the G196A polymorphism was performed using validated methods: four studies (Hong et al. 2003; Masaki et al. 2003; Parsian et al. 2004; Nishimura et al. 2005) used PCR restriction fragment length polymorphism,
Momose et al. (2002) performed genotyping with an allele-specific oligonucleotide, and Hakansson et al. (2003) performed genotyping with a pyrosequencing method.

\section{Summary statistics}

In total, the studies included 1,419 cases and 1,406 controls. The prevalence of allele A was $43 \%$ and $42 \%$ for the PD and control groups, respectively. The prevalence of homozygotes AA among PD patients and controls was $21 \%$ and $19 \%$, respectively. The prevalence of GG among PD patients and the controls was 34\% and $35 \%$, respectively. The prevalence of heterozygotes AG among PD patients and controls was $45 \%$ and $47 \%$, respectively (Table 2 ).

In two studies (Momose et al. 2002; Parsian et al. 2004), the distribution of genotypes in the control group was not in HWE $(P=0.03$ and $<0.01$, respectively), indicating genotyping errors and/or population stratification ( $\mathrm{Xu}$ et al. 2002; Zintzaras and Hadjigeorgiou 2004). Therefore, a sensitivity analysis was carried out for these studies; however, the results produced should be interpreted with caution.

Main results, subgroup, and sensitivity analyses

The main analysis for investigating the association of allele $A$ and the risk of developing $P D$ relative to allele $G$ showed large heterogeneity $\left(P=0.07, I^{2}=51 \%\right)$ between the six studies, thus the RE pooled OR was not significant $[\mathrm{OR}=1.00 ; 95 \%$ CI $(0.85,1.18)]$ (Table 3 and Fig. 1).

Table 1 Characteristics of the case-control studies considered in the meta-analysis. PD Parkinson's disease

\begin{tabular}{|c|c|c|c|c|}
\hline $\begin{array}{l}\text { First author, } \\
\text { year }\end{array}$ & Country & $\begin{array}{l}\text { Racial } \\
\text { descent }\end{array}$ & $\begin{array}{l}\text { Selection criteria and } \\
\text { demographic data of cases }\end{array}$ & $\begin{array}{l}\text { Selection criteria and demographic } \\
\text { data of controls }\end{array}$ \\
\hline Momose, 2002 & Japan & East Asian & $\begin{array}{l}232 \text { idiopathic PD patients }(\mathrm{M} / \mathrm{F}=114 / 118) \\
\text { mean age of onset } 54.1 \pm 10.5 \text { years; } 13 \\
\text { patients had a positive family history of } \mathrm{PD}^{\mathrm{a}}\end{array}$ & 249 normal controls $(\mathrm{M} / \mathrm{F}=127 / 122)$ \\
\hline Hakansson, 2003 & Sweden & White & $\begin{array}{l}257 \text { PD patients fulfilled the PDS } \\
\text { Brain Bank criteria; } \\
8 \text { cases had more than one affected relative. } \\
\text { Mean age at onset }=60 \text { years }\end{array}$ & 307 controls \\
\hline Hong, 2003 & China & East Asian & $\begin{array}{l}107 \text { idiopathic } \mathrm{PD} \text { patients }(\mathrm{M} / \mathrm{F}=77 / 30) \text {, } \\
\text { mean age } 68.2 \pm 10.4 \text { years }^{\mathrm{a}}\end{array}$ & $\begin{array}{l}103 \text { controls }(\mathrm{M} / \mathrm{F}=69 / 34) \\
\text { mean age } 66.3 \pm 14.2 \text { years. } \\
\text { Age-sex matched }\end{array}$ \\
\hline Masaki, 2003 & Japan & East Asian & $\begin{array}{l}291 \text { idiopathic PD patients, } \\
\text { mean age } 65.7 \pm 8.99 \text { years }\end{array}$ & $\begin{array}{l}291 \text { normal controls, mean age } \\
65.6 \pm 9.21 \text { years. Age-sex matched }\end{array}$ \\
\hline Parsian, 2004 & UK & White & $\begin{array}{l}206 \text { unrelated sporadic PD patients with a negative } \\
\text { family history, mean age } 62 \pm 11.8 \text { years. Diagnosis } \\
\text { was based on criteria described } \\
\text { in Racette et al. (1999) }\end{array}$ & $\begin{array}{l}195 \text { normal controls, mean age } \\
62 \pm 14 \text { years. Age-sex matched }\end{array}$ \\
\hline Nishimura, 2005 & Japan & East Asian & $\begin{array}{l}327 \mathrm{PD} \text { patients }(\mathrm{M} / \mathrm{F}=129 / 198) \\
\text { mean age } 66.4 \pm 9.9 \text { years }\end{array}$ & $\begin{array}{l}275 \text { unrelated healthy controls, } \\
\text { mean age } 68.4 \pm 10.5 \text { years }\end{array}$ \\
\hline
\end{tabular}

${ }^{a}$ Diagnosis was based on the presence of two or more of the cardinal features of PD and there were no atypical features or secondary causes of Parkinsonism 
Table 2 Distribution of brain-derived neurotrophic factor (BDNF) genotypes, and their allelic frequency, for PD patients and controls

\begin{tabular}{|c|c|c|c|c|c|c|c|c|c|c|c|}
\hline \multirow{2}{*}{$\begin{array}{l}\text { First author, } \\
\text { year }\end{array}$} & \multirow{2}{*}{$\begin{array}{l}\text { Racial } \\
\text { descent }\end{array}$} & \multicolumn{6}{|c|}{ Distribution of BDNF genotypes ${ }^{\mathrm{a}}$} & \multicolumn{4}{|c|}{ Frequency of BDNF alleles } \\
\hline & & PD & Control & $\mathrm{PD}$ & Control & PD & Control & PD & Control & $\mathrm{PD}$ & Control \\
\hline Momose, 2002 & East Asian & $48(21)$ & $30(13)$ & $117(51)$ & $130(55)$ & $66(29)$ & $76(32)$ & $213(46)$ & $190(40)$ & $249(54)$ & $282(60)$ \\
\hline $\begin{array}{l}\text { Hakansson, } \\
2003\end{array}$ & White & $7(3)$ & $12(4)$ & $79(31)$ & $85(28)$ & $171(67)$ & $209(68)$ & $93(18)$ & 109 (18) & $421(82)$ & $503(82)$ \\
\hline Parsian, 2004 & White & $98(48)$ & $88(45)$ & $96(47)$ & $103(53)$ & $12(6)$ & $4(2)$ & $292(71)$ & 279 & $120(29)$ & $111(28)$ \\
\hline $\begin{array}{l}\text { Nishimura, } \\
2005\end{array}$ & East Asian & $64(20)$ & $47(17)$ & $171(52)$ & $140(51)$ & $92(28)$ & $88(32)$ & $299(46)$ & $234(43)$ & $355(54)$ & $316(57)$ \\
\hline
\end{tabular}

${ }^{\mathrm{a}}$ Corresponding percentages are given in brackets

In subgroup analysis, there was large heterogeneity $\left(P=0.02, I^{2}=70 \%\right)$ between the studies performed in East Asian populations, and the RE pooled ORs was not significant $[\mathrm{OR}=1.00 ; 95 \% \mathrm{CI}(0.78,1.28)]$ (Table 3). The studies in Whites showed no heterogeneity $\left(P=0.82, I^{2}=0 \%\right)$ and produced not significant result $[\mathrm{FE} \mathrm{OR}=0.99(95 \% \mathrm{CI}(0.80,1.23)]$.

In sensitivity analysis (exclusion of the two studies with controls not in HWE), there was large betweenstudy heterogeneity either for all studies in HWE
$\left(P=0.10, I^{2}=52 \%\right)$, or for East Asian studies in HWE $\left(P=0.05, I^{2}=66 \%\right)$. In Whites, there was only one study in HWE (Table 3). In the analysis for all studies in HWE, and in East Asians in HWE, the RE ORs were not significant: $\mathrm{OR}=0.94[95 \%$ CI $(0.77,1.15)]$ and $\mathrm{OR}=0.92[95 \%$ CI $(0.70,1.21)]$, respectively.

The genotype contrast of the homozygotes, and the dominant and recessive models for the effect of the A allele, produced the same pattern of results with the allele contrast, indicating no significant association

Table 3 Pooled odds ratios (ORs) with the corresponding 95\% confidence intervals (CIs) and the heterogeneity significance for main analysis, subgroup, and sensitivity analyses. $H W E$ Hardy-Weinberg equilibrium

\begin{tabular}{|c|c|c|c|c|c|c|c|}
\hline Genetic contrasts & $\begin{array}{l}\text { Population and subgroups } \\
\text { under analysis }\end{array}$ & $\begin{array}{l}\text { Studies } \\
(n)\end{array}$ & $\begin{array}{l}\text { Alleles/genotypes } \\
(n)\end{array}$ & $\begin{array}{l}\text { Fixed effects } \\
\text { OR }(95 \% \mathrm{CI})\end{array}$ & $\begin{array}{l}\text { Random effects } \\
\text { OR }(95 \% \mathrm{CI})\end{array}$ & $\begin{array}{l}I^{2} \\
(\%)\end{array}$ & $Q$-test $P$-value \\
\hline \multirow[t]{4}{*}{ A vs $G$} & All & 6 & 5,650 & $1.00(0.90,1.12)$ & $1.00(0.85,1.18)$ & 51 & 0.07 \\
\hline & East Asians & 4 & 3,722 & $1.00(0.88,1.14)$ & $1.00(0.78,1.28)$ & 70 & 0.02 \\
\hline & $\begin{array}{l}\text { East Asians } \\
\text { in HWE }\end{array}$ & 3 & 2,788 & $0.93(0.80,1.08)$ & $0.92(0.70,1.21)$ & 66 & 0.05 \\
\hline & Whites & 2 & 1,928 & $0.99(0.80,1.23)$ & $0.99(0.80,1.23)$ & 0 & 0.82 \\
\hline \multirow{5}{*}{ AA vs $\mathrm{GG}$} & All in HWE & 4 & 1,109 & $0.86(0.64,1.14)$ & $0.85(0.57,1.27)$ & 42 & 0.16 \\
\hline & East Asians & 4 & 930 & $1.03(0.79,1.35)$ & $1.05(0.63,1.75)$ & 71 & 0.02 \\
\hline & $\begin{array}{l}\text { East Asians } \\
\text { in HWE }\end{array}$ & 3 & 710 & $0.87(0.64,1.18)$ & $0.87(0.53,1.44)$ & 60 & 0.08 \\
\hline & Whites & 2 & 601 & $0.54(0.26,1.12)$ & $0.55(0.26,1.15)$ & 0 & 0.40 \\
\hline & Whites in HWE & 1 & 399 & $0.71(0.27,1.85)$ & & & \\
\hline \multirow{2}{*}{$\mathrm{AA}$ vs $(\mathrm{AG}+\mathrm{GG})$} & Whites & 2 & 964 & $1.03(0.72,1.47)$ & $1.03(0.72,1.48)$ & 0 & 0.37 \\
\hline & Whites in HWE & 1 & 563 & $0.69(0.27,1.77)$ & & & \\
\hline \multirow[t]{6}{*}{$(\mathrm{AG}+\mathrm{AA})$ vs $\mathrm{GG}$} & All & 6 & 2,825 & $0.94(0.80,1.12)$ & $0.91(0.69,1.20)$ & 56 & 0.04 \\
\hline & All in HWE & 4 & 1,957 & $0.92(0.76,1.12)$ & $0.91(0.67,1.23)$ & 57 & 0.07 \\
\hline & East Asians & 4 & 1,861 & $0.94(0.77,1.14)$ & $0.93(0.67,1.29)$ & 61 & 0.05 \\
\hline & $\begin{array}{l}\text { East Asians } \\
\text { in HWE }\end{array}$ & 3 & 1,394 & $0.87(0.69,1.09)$ & $0.85(0.56,1.28)$ & 66 & 0.05 \\
\hline & Whites & 2 & 964 & $0.96(0.69,1.34)$ & $0.69(0.23,2.10)$ & 72 & 0.06 \\
\hline & Whites in HWE & 1 & 563 & $1.08(0.76,1.54)$ & n.a. & n.a. & n.a. \\
\hline
\end{tabular}

\footnotetext{
${ }^{\mathrm{a} N o t}$ applicable
} 

neurotrophic factor (BDNF) polymorphism and the risk of Parkinson's disease (PD): contrast of allele A against allele $\mathrm{G}$. The odds ratio (OR) with the corresponding $95 \%$ confidence interval (CI) for each study is shown. The random effects (RE) pooled ORs for all studies, for studies in Hardy-Weinberg equilibrium (HWE), and for studies according to racial descent are shown. The horizontal axis is plotted on a log scale
Fig. 1 G196A brain-derived

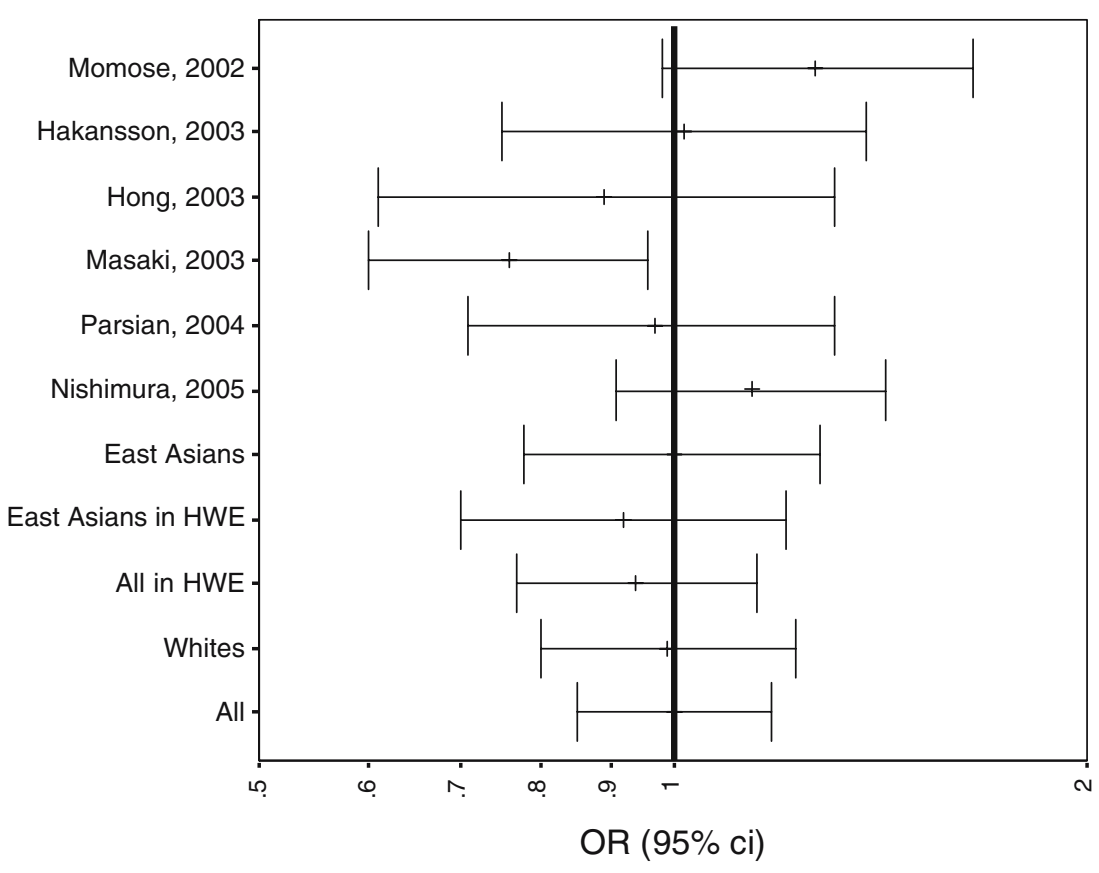

(Table 3 and Fig. 2). Adjusted pooled ORs were not calculated, since all studies provided unadjusted and unstratified estimates.

\section{Potential bias}

None of the studies reported that genotyping was blinded to clinical status. Cumulative meta-analysis and recursive meta-analysis for the allelic contrast showed that the RE pooled OR decreased from 1.27 in 2002 (first study) to 0.96 in 2004 and then increased to 1.00 in 2005. The Egger test and the Begg-Mazumdar test indicated that there is no differential magnitude of effect in large vs small studies ( $P=0.83$ and 0.35 , respectively). However, this result might not be so reliable since the number of studies is small (Ioannidis et al. 2003). There is no statistical difference between the OR of the first study and the pooled OR of the subsequent studies $(z=1.86, P=0.06)$.

\section{Discussion}

The present meta-analysis included data from six case-control association studies that investigated the
Fig. 2 G196A BDNF

polymorphism and the risk of PD: contrast of dominant and recessive models of the A allele. The OR with the corresponding 95\% CI for each study is shown. The RE pooled ORs for all studies, for studies in HWE, and for studies according to racial descent are shown. The horizontal axis is plotted on a log scale

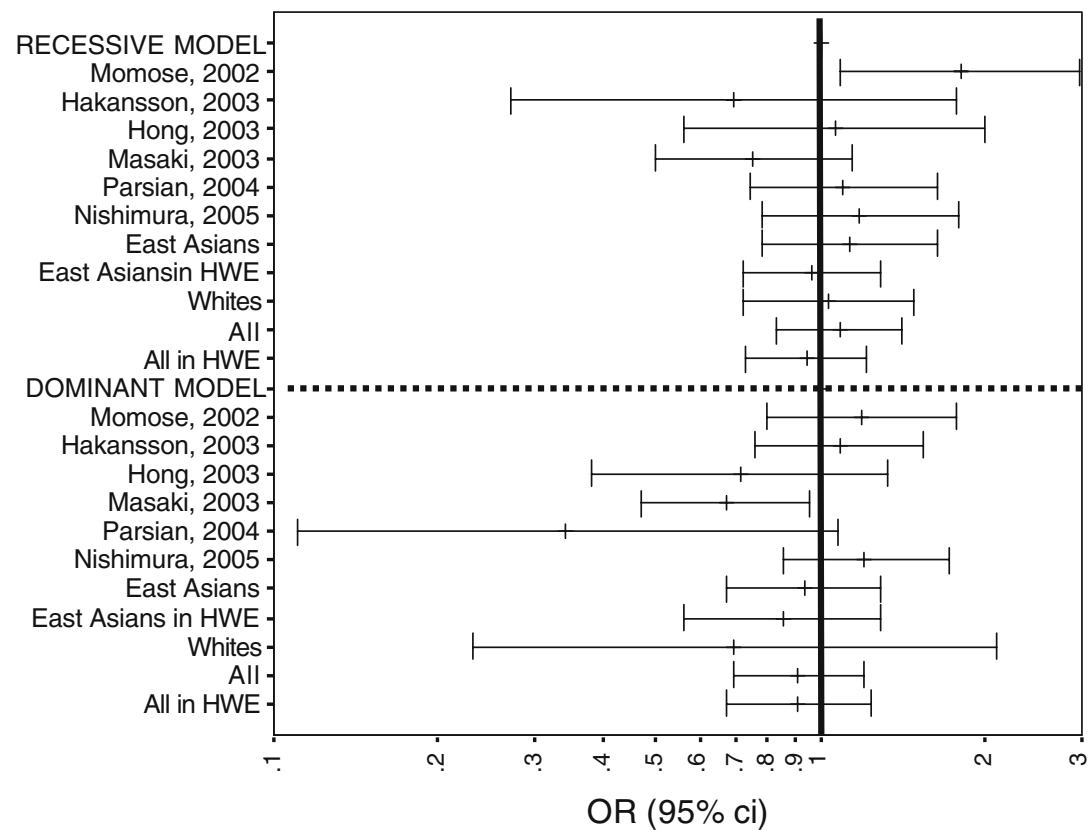


relationship between the G196A BDNF polymorphism and PD. Population association studies are an attractive strategy in defining genetic factors contributing to the development of complex disease such as PD (Cardon and Bell 2001). Recently, a number of meta-analyses investigating the association between gene polymorphisms and PD have been published. These meta-analyses involved: alpha-synuclein (Mellick et al. 2005), the tau gene (Zhang et al. 2005), the paraoxonase 1 gene (Zintzaras and Hadjigeorgiou 2004), APOE-[varepsilon2] (Huang et al. 2004), the CYP2D6 polymorphism (Persad et al. 2003), and the catechol- $O$-methyltransferase gene (Mizuta et al. 2000).

In this meta-analysis, a total of 1,419 PD patients and 1,406 controls free of PD were analysed. However, these numbers are relatively small for making inferences on the effect of alleles and genotypes (Ioannidis et al. 2003). The strength of the present analysis is based on the aggregation of published case-control studies, thus there is more information with which to investigate the existence of genetic associations (Muncer 2002; Zintzaras and Hadjigeorgiou 2004).

The first published study included here (East Asians; Momose et al. 2002) supported the view that homozygocity (AA) can be considered a major risk factor for susceptibility to $\mathrm{PD}$, but the controls included were not in HWE and, therefore, these results should be considered dubious. However, another study (Masaki et al. 2003 ) in East Asians produced the opposite result. The main meta-analysis and the subgroup and sensitivity analyses indicated lack of association between G196A BDNF polymorphism and $\mathrm{PD}$, and large heterogeneity between study results. In addition, the contrast of homozygotes and the dominant and recessive models produced the same pattern of results.

In the published studies, there was no difference in results between large and small studies; therefore, this was not a source of potential bias. Parsian et al. (2004) and Nishimura et al. (2005) reported that G196A BDNF gene polymorphism is in linkage disequilibrium with C207T and C240T polymorphisms, respectively. However, the discrepancy in the reported results might be due to other locus that are probably in linkage disequilibrium and that affect susceptibility to PD. The PD patients included in the meta-analysis were well-defined, although they were not identical in terms of disease severity and other clinical and demographic manifestations. This between-case variability might be a possible confounding factor in the role of G196A BDNF gene polymorphism. In the subgroup analysis by racial descent, Chinese and Japanese were analysed together, since these two populations are more homogeneous to each other, than to Whites (Thomas and White 2002; Ioannidis et al. 2004; Zintzaras and Hadjigeorgiou 2004; Zintzaras and Stefanidis 2005).

Overall, the meta-analysis supported no association between G196A BDNF gene polymorphism and PD, and revealed large heterogeneity between studies. However, this conclusion was based on a relatively small number of studies and participants, and any inferences have to be made with caution. PD is a complex disease with a multifactorial aetiology and a minor contributing pathogenetic role of G196A BDNF gene polymorphism in specific cases in cooperation with other factors, cannot therefore be excluded. The relationship between G196A BDNF gene polymorphism and PD thus remains an unresolved issue, and further exploration of the involvement of the BDNF gene in the susceptibility to $\mathrm{PD}$ with more rigorous population association studies is required.

\section{References}

Begg CB, Mazumdar M (1994) Operating characteristics of a rank correlation test for publication bias. Biometrics 50:1088-1101

Cardon LR, Bell JI (2001) Association study designs for complex diseases. Nat Genet Rev 2:91-99

Cochran WG (1954) The combination of estimates from different experiments. Biometrics 10:101-129

Dawson TM, Dawson VL (2003) Rare genetic mutations shed light on the pathogenesis of Parkinson disease. J Clin Invest 111:145151

Egan MF, Kojima M, Callicott JH, Goldberg TE, Kolachana BS, Bertolino A, Zaitsev E, Gold B, Goldman D, Dean M, Lu B, Weinberger DR (2003) The BDNF val66met polymorphism affects activity-dependent secretion of BDNF and human memory and hippocampal function. Cell 112:257-269

Egger M, Davey SG, Schneider M, Minder C (1997) Bias in metaanalysis detected by a simple, graphical test. BMJ 315:629-634

Hakansson A, Melke J, Westberg L, Shahabi HN, Buervenich S, Carmine A, Klingborg K, Grundell MB, Schulhof B, Holmberg B, Ahlberg J, Eriksson E, Sydow O, Olson L, Johnels B, Nissbrandt H (2003) Lack of association between the BDNF Val66Met polymorphism and Parkinson's disease in a Swedish population. Ann Neurol 53:823

Higgins JP, Thompson SG, Deeks JJ, Altman DG (2003) Measuring inconsistency in meta-analyses. BMJ 327:557-560

Holsinger RM, Schnarr J, Henry P, Castelo VT, Fahnestock M (2000) Quantitation of BDNF mRNA in human parietal cortex by competitive reverse transcription-polymerase chain reaction: decreased levels in Alzheimer's disease. Brain Res Mol Brain Res 76:347-354

Hong CJ, Liu HC, Liu TY, Lin CH, Cheng CY, Tsai SJ (2003) Brain-derived neurotrophic factor (BDNF) Val66Met polymorphisms in Parkinson's disease and age of onset. Neurosci Lett 353:75-77

Huang X, Chen PC, Poole C (2004) APOE-[varepsilon]2 allele associated with higher prevalence of sporadic Parkinson disease. Neurology 62:2198-2202

Hyman C, Hofer M, Barde YA, Juhasz M, Yancopoulos GD, Squinto SP, Lindsay RM (1991) BDNF is a neurotrophic factor for dopaminergic neurons of the substantia nigra. Nature 350:230-232

Ioannidis JP, Trikalinos TA, Ntzani EE, Contopoulos-Ioannidis DG (2003) Genetic associations in large versus small studies: an empirical assessment. Lancet 361:567-571

Ioannidis JP, Ntzani EE, Trikalinos TA (2004) "Racial" differences in genetic effects for complex diseases. Nat Genet 36:1312-1318

Lau J, Antman EM, Jimenez-Silva J, Kupelnick B, Mosteller F, Chalmers TC (1992) Cumulative meta-analysis of therapeutic trials for myocardial infarction. N Engl J Med 327:248-254

Lau J, Ioannidis JP, Schmid CH (1997) Quantitative synthesis in systematic reviews. Ann Intern Med 127:820-826

Lewis PO, Zaykin D (2001) Genetic Data Analysis: computer program for the analysis of allelic data. Version 1.0 (d16c). Available from http://lewis.eeb.uconn.edu/lewishome/software.html 
Liu QR, Walter D, Drgon T, Polesskaya O, Lesnick TG, Strain KJ, de Andrade M, Bower JH, Maraganore DM, Uhl GR (2005) Human brain neurotrophic factor (BDNF) genes, splicing patterns, and assessments of associations with substance abuse and Parkinson's disease. Am J Med Genet B Neuropsychiatr Genet 134:93-103

Masaki T, Matsushita S, Arai H, Takeda A, Itoyama Y, Mochizuki H, Kamakura K, Ohara S, Higuchi S (2003) Association between a polymorphism of brain-derived neurotrophic factor gene and sporadic Parkinson's disease. Ann Neurol 54:276-277

Mellick GD, Maraganore DM, Silburn PA (2005) Australian data and meta-analysis lend support for alpha-synuclein (NACPRep1) as a risk factor for Parkinson's disease. Neurosci Lett 375:112-116

Mizuta I, Mizuta E, Yamasaki S, Kuno S, Yasuda M, Tanaka C (2000) Meta-analysis of polymorphism of the catechol- $O$ methyltransferase gene in relation to the etiology of Parkinson's disease in Japan. Mov Disord 15:1013-1014

Mogi M, Togari A, Kondo T, Mizuno Y, Komure O, Kuno S, Ichinose H, Nagatsu T (1999) Brain-derived growth factor and nerve growth factor concentrations are decreased in the substantia nigra in Parkinson's disease. Neurosci Lett 270:45-48

Momose Y, Murata M, Kobayashi K, Tachikawa M, Nakabayashi Y, Kanazawa I, Toda T (2002) Association studies of multiple candidate genes for Parkinson's disease using single nucleotide polymorphisms. Ann Neurol 51:133-136

Muncer S (2002) Response to: "Power dressing and meta-analysis: incorporating power analysis into meta-analysis". J Adv Nurs $38: 274-280$

Murer MG, Yan Q, Raisman-Vozari R (2001) Brain-derived neurotrophic factor in the control human brain, and in Alzheimer's disease and Parkinson's disease. Prog Neurobiol 63:71-124

Nishimura M, Kuno S, Kaji R, Kawakami H (2005) Brain-derived neurotrophic factor gene polymorphisms in Japanese patients with sporadic Alzheimer's disease, Parkinson's disease, and multiple system atrophy. Mov Disord 20:1031-1033

Parsian A, Sinha R, Racette B, Zhao JH, Perlmutter JS (2004) Association of a variation in the promoter region of the brainderived neurotrophic factor gene with familial Parkinson's disease. Parkinsonism Relat Disord 10:213-219

Persad AS, Stedeford T, Tanaka S, Chen L, Banasik M (2003) Parkinson's disease and CYP2D6 polymorphism in Asian populations: a meta-analysis. Neuroepidemiology 22:357-361

Piccini P, Burn DJ, Ceravolo R, Maraganore D, Brooks DJ (1999) The role of inheritance in sporadic Parkinson's disease: evidence from a longitudinal study of dopaminergic function in twins. Ann Neurol 45:577-582
Racette BA, Rundle M, Parsian A, Perlmutter JS (1999) Evaluation of a screening questionnaire for genetic studies of Parkinson's disease. Am J Med Genet 88:539-543

Schapira AH (1997) Pathogenesis of Parkinson's disease. Baillieres Clin Neurol 6:15-36

Sveinbjornsdottir S, Hicks AA, Jonsson T, Petursson H, Gugmundsson G, Frigge ML, Kong A, Gulcher JR, Stefansson K (2000) Familial aggregation of Parkinson's disease in Iceland. N Engl J Med 343:1765-1770

Thomas DC, White JS (2002) Point: population stratification: a problem for case-control studies of candidate-gene associations? Cancer Epidemiol Biomarkers Prev 11:505-512

Toda T, Momose Y, Murata M, Tamiya G, Yamamoto M, Hattori N, Inoko H (2003) Toward identification of susceptibility genes for sporadic Parkinson's disease. J Neurol 250[Suppl]:III/40III $/ 43$

Weir BS (1996) Genetic data analysis II: methods for discrete population genetic data. Sinauer, Sunderland, MA

Whitehead A (1997) A prospectively planned cumulative metaanalysis applied to a series of concurrent clinical trials. Stat Med 16:2901-2913

Whitehead A (2002) Meta-analysis of controlled clinical trials Wiley, Chichester

Wirdefeldt K, Burgess CE, Westerberg L, Payami H, Schalling (2003) A linkage study of candidate loci in familial Parkinson's disease. Biomed Cent Neurol 3:6

Xu J, Turner A, Little J, Bleecker ER, Meyers DA (2002) Positive results in association studies are associated with departure from Hardy-Weinberg equilibrium: hint for genotyping error? Hum Genet 111:573-574

Zhang J, Song Y, Chen H, Fan D (2005) The tau gene haplotype h1 confers a susceptibility to Parkinson's disease. Eur Neurol $53: 15-21$

Zintzaras E, Hadjigeorgiou GM (2004) Association of paraoxonase 1 gene polymorphisms with risk of Parkinson's disease: a metaanalysis. J Hum Genet 49:474-481

Zintzaras E, Ioannidis JP (2005) Heterogeneity testing in metaanalysis of genome searches. Genet Epidemiol 28:123-137

Zintzaras E, Stefanidis I (2005) Association between the GLUT1 gene polymorphism and the risk of diabetic nephropathy: a meta-analysis. J Hum Genet 50:84-91

Zintzaras E, Chatzoulis DZ, Karabatsas CH, Stefanidis I (2005) The relationship between C677T methylenetetrahydrofolate reductase gene polymorphism and retinopathy in type 2 diabetes: a meta-analysis. J Hum Genet 50:267-275 